\title{
Structure and Dielectric Studies of $\mathrm{Sn}^{4+} / \mathrm{Er}^{3+}$ co-doped $\mathrm{BaTiO}_{3}$ Nano-Powders
}

\begin{abstract}
R. Mahani ${ }^{a, *}$, O. El-Sayed ${ }^{b}$, S.K. El-Mahy ${ }^{b}$ And I.K. Battisha ${ }^{c}$
${ }^{a}$ Microwave Physics and Dielectrics Dept., National Research Centre, 33 El Bohouth Str., 12622 Giza, Egypt

${ }^{b}$ Physics Department, Faculty of Women for Arts, Science and Education, Ain Shams University, Cairo, Egypt

${ }^{c}$ Solid State Physics Dept., National Research Centre, 33 El Bohouth Str., 12622 Giza, Egypt

(Received November 27, 2019; revised version December 23, 2019; in final form December 24, 2019)

Nanocrystalline barium titanate $\left(\mathrm{BTO}_{3}\right)$ powders annealed at $1050{ }^{\circ} \mathrm{C}$ for $4 \mathrm{~h}$, were synthesized using the sol-gel method and the effects of $\mathrm{Sn}^{4+} / \mathrm{Er}^{3+}$ co-doping $\left(\mathrm{BTSO}_{3}: 2 \mathrm{Er}\right)$ on microstructure and dielectric properties of $\mathrm{BTO}_{3}$ powders, were investigated. The crystalline structure, microstructure, molecular structure, and dielectric properties were investigated using X-ray powder diffraction, field emission scanning electron microscope, with energy dispersive X-ray analysis, the Fourier transform infra-red spectroscopy, and dielectric spectrometer. X-ray powder diffraction analysis confirmed the formation of both $\mathrm{BTO}_{3}$ and $\mathrm{BTSO}_{3}: 2 \mathrm{Er}$ in a single tetragonal phase. For $\mathrm{BTSO}_{3}: 2 \mathrm{Er}$ sample, the particle size decreased from 64 for pure $\mathrm{BTO}_{3}$ to $57.11 \mathrm{~nm}$ for $\mathrm{BTSO}{ }_{3}: 2 \mathrm{Er}$, inhibiting grain growth upon co-doping with $\mathrm{Sn}^{4+} / \mathrm{Er}^{3+}$ ions. Further, according to field emission scanning electron microscope observations, the Fourier transform infra-red spectroscopy analysis showed a new band assigned to $\mathrm{M}-\mathrm{O}$. Correspondingly, $\mathrm{BTSO}_{3}: 2 \mathrm{Er}$ showed an anomaly relaxation peak whose maximum was positioned at temperature value $\left(174^{\circ} \mathrm{C}\right)$ higher than the Curie temperature $\left(T_{\mathrm{C}}\right)$ according to permittivity measurements. Its $T_{\mathrm{C}}$ shifted from 125 to $103{ }^{\circ} \mathrm{C}$ and permittivity considerably increased to become ten times greater than that of pure $\mathrm{BTO}_{3}$, revealing enhancements of dielectric properties upon doping with $\mathrm{Sn}^{4+} / \mathrm{Er}^{3+}$ ions. Also, AC conductivity for $\mathrm{BTSO}_{3}: 2 \mathrm{Er}$ sample considerably increased due to the formation of excess oxygen vacancies.
\end{abstract}

DOI: 10.12693/APhysPolA.137.410

PACS/topics: nanopowder, X-ray diffraction, barium titanate, dielectric properties

\section{Introduction}

Barium titanate $\left(\mathrm{BTO}_{3}\right)$ has been considered as one of the ferroelectric materials most frequently used in manufacturing various microelectronic devices due to its unique electrical properties, mechanical and chemical stability [1]. Much attention has been paid to prepare such ceramics with an average grain size below $100 \mathrm{~nm}$ to improve their electrical properties to be used in fabricating multilayer ceramic capacitors (MLCCs) with high efficiency. However, MLCCs based $\mathrm{BTO}_{3}$ have still some drawbacks originating from the degradation of ferroelectric and dielectric properties when the grain size decreases [2]. Many attempts were made to overcome such problems and to prepare $\mathrm{BTO}_{3}$ sample with fine particle size, controlled stoichiometry, and uniformity. Currently, there are two methods for synthesizing $\mathrm{BTO}_{3}$ sample: solid-phase [3] and liquid-phase methods [4]. The traditional solid phase method of high sintering temperatures still has some drawbacks such as serious agglomeration and coarse grains. Instead, the sol-gel method of low sintering temperature provides a new approach to the preparation of high purity, uniform, and ultrafine metal oxide nanoparticles in a few steps [2]. Thus, in the current study, the sol-gel method has been used to prepare pure $\left(\mathrm{BTO}_{3}\right)$ and $\mathrm{Sn}^{4+} / \mathrm{Er}^{3+}$ co-doped barium titanate $\left(\mathrm{BTSO}_{3}: 2 \mathrm{Er}\right)$ nanopowders.

*corresponding author; e-mail: rmsoliman66@yahoo.com
The doping mechanism and influence of the large rareearth ions on structural and electrical properties of $\mathrm{BTO}_{3}$ ceramics have been extensively studied $[5,6]$. By definition, the relaxor ferroelectrics are well characterized by broad relaxation peaks in their dielectric spectra which shifted to higher temperatures with increasing frequency $[7,8]$. The relaxor phenomenon was first evidenced in $\mathrm{Ba}\left(\mathrm{Ti}_{1-x}-\mathrm{Sn}_{x}\right) \mathrm{O}_{3}$, and is currently ascribed to the development of polar nanoregions (PNRs) $[9,10]$. On the other hand, the polarized domains in pure $\mathrm{BaTiO}_{3}$ exhibit a sharp relaxation peak at the phase transition temperature, i.e. the Curie temperature $\left(T_{\mathrm{C}} \sim 130^{\circ} \mathrm{C}\right)$ [11]. Several types of research reported a diffused phase transition in $\mathrm{Ba}\left(\mathrm{Ti}_{0.7} \mathrm{Sn}_{0.3}\right) \mathrm{O}_{3}$ that achieves complete relaxor characteristics [12]. This results in increase of permittivity, tunability under biasing field, as well as a reduction of the low-frequency dielectric losses. The addition of rare-earth $\left(\mathrm{RE}^{3+}\right)$ elements to $\mathrm{BTO}_{3}$ was found to be useful for producing semiconducting materials which in turn enables the development of positive temperature coefficient resistors (PTCR) [13]. The special interest is given for rare-earth cations because some of them exhibit amphoteric behavior when they incorporated into the $\mathrm{BTO}_{3}$ structure. For instance, lanthanide ions from $\mathrm{Sm}^{3+}$ to $\mathrm{Er}^{3+}$, having a particle size between $\mathrm{Ba}^{2+}$ and $\mathrm{Ti}^{4+}$, can be accommodated either at $\mathrm{A}$ or $\mathrm{B}$ lattice sites, depending on their concentrations and stoichiometry of the hosting structure [12, 14, 15]. Erbium $\left(\mathrm{Er}^{3+}\right)$ has been widely used because of its great technological interest [16]. As its particle size $(0.89 \AA)$ value lies between $\mathrm{Ba}^{2+}(1.61 \AA)$ and $\mathrm{Ti}^{4+}(0.605 \AA)$, 
it would occupy Ti-site to improve the stability of $\mathrm{BTO}_{3}$ at this location $[17,18]$. Based on the above, the main objective of the current study is to investigate two subjects $\mathrm{BTO}_{3}$ and $\mathrm{BTSO}_{3}: 2 \mathrm{Er}$. The first is to prepare these ceramics on the nanoscale having sufficiently high permittivity to be useful for electrical capacitors and relaxors fabrication. The second concerns the effect of $\mathrm{Sn}^{4+} / \mathrm{Er}^{3+}$ co-doping on their microstructure, crystalline structure, and dielectric properties. Sample's structure was characterized using X-ray diffraction (XRD) and field emission scanning electron microscopy (FESEM) whereas their dielectric properties were studied over a temperature range $\left(-50^{\circ} \mathrm{C}\right.$ to $\left.200^{\circ} \mathrm{C}\right)$ at different frequencies.

\section{Materials and methods}

\subsection{Synthesis procedure}

The chemical starting materials used in the present study were barium acetate $\mathrm{Ba}\left(\mathrm{CH}_{3} \mathrm{COO}\right)_{2}$ (Aldrich $99 \%$ ), titanium(IV) $n$-butoxide $\mathrm{Ti}\left(\mathrm{OC}_{4} \mathrm{H}_{9}\right)_{4}$ (Alfa Aesar $99+\%$ ). $35 \mathrm{ml}$ acetyl acetone $\mathrm{C}_{5} \mathrm{H}_{8} \mathrm{O}_{2}$ (Aldrich 99+\%) and $20 \mathrm{ml}$ acetic acid $\left(\mathrm{C}_{2} \mathrm{H}_{4} \mathrm{O}_{2}\right)$ diluted with distilled water (HAc) $-\mathrm{H}_{2} \mathrm{O}$ were selected as solvents of $6.662 \mathrm{~g}$ titanium(IV) $n$-butoxide and $5 \mathrm{~g}$ barium acetate, respectively. Barium titanate $\left(\mathrm{BTO}_{3}\right)$ was obtained by reacting to two solutions of barium acetate and titanium(IV) $n$-butoxide (Sol 1) for $1 \mathrm{~h}$ on the stirrer. To obtain $\mathrm{BTSO}_{3}: 2 \mathrm{Er}\left(\mathrm{BaTi}_{0.88} \mathrm{Sn}_{0.1} \mathrm{Er}_{0.02} \mathrm{O}_{3}\right)$ Sol 1 was mixed with tin solution $\left(10 \mathrm{~mol} . \% \mathrm{SnCl}_{4} \cdot 5 \mathrm{H}_{2} \mathrm{O}\right.$ (Strem Chemicals, Incorporated), dissolved in $16 \mathrm{ml}$ isopropanol) for 15 min on the stirrer (Sol 2), and then added erbium solution $\left(2 \mathrm{~mol} . \% \mathrm{Er}\left(\mathrm{NO}_{3}\right)_{3} \cdot 5 \mathrm{H}_{2} \mathrm{O}\right.$ (Aldrich $\left.99+\%\right)$ dissolved in $5 \mathrm{ml}$ distilled water), and then the mixture was stirred on hotplate for $50 \mathrm{~min}$ (Sol 3). As a result, gel was formed at $130^{\circ} \mathrm{C}$ which was then annealed in air for $4 \mathrm{~h}$ at $1050^{\circ} \mathrm{C}$ (using Muffle furnace type Carbolite CWF1200) and finally small crystallized samples of $\mathrm{BTO}_{3}$ and $\mathrm{BTSO}_{3}: 2 \mathrm{Er}$ were obtained.

For dielectric measurements, the fine ceramic sample was pressed into samples-shaped pellets having a diameter of $10 \mathrm{~mm}$ and a thickness of $2.4 \mathrm{~mm}$ under pressure of $40 \mathrm{MPa}$ at room temperature. Then, both surfaces of each sample were coated with a silver paste to ensure good contacting.

\subsection{Characterization of nanopowders}

To examine the crystal structure of $\mathrm{BTO}_{3}$ and $\mathrm{BTSO}_{3}: 2 \mathrm{Er}$ nanopowders, XRD measurements were performed. Philips X-ray diffractometer having monochromatized $\mathrm{Cu} K_{\alpha 1}(\lambda=1.5406 \AA)$ of power $40 \mathrm{kV} \times 30 \mathrm{~mA}$, was used. The crystallite size $(G)$ was calculated from the Scherrer equation [19]:

$$
G=\frac{K \lambda}{D \cos (\theta)},
$$

where $K=0.89$ is the Scherrer constant, $\lambda$ is the wavelength, $D$ is the full width (in radians) of the peak at half maximum (FWHM) intensity, and $\theta$ is the diffracted angle. FESEM together with energy dispersive X-ray (EDX) analysis were provided with a variable pressure FESEM instrument (FEI, model: Quanta 250 FEG) to determine the crystalline phases and elements. To achieve this, the samples were gold-sputtered using Edwards S150A Sputter coater to make the images more obvious. The sample's chemical structure was characterized using the Fourier transform infra-red spectroscopy using Thermo Nicolet, FT-IR, and NEXUS in the range from 400 up to $4000 \mathrm{~cm}^{-1}$.

The dielectric measurements were carried out by inserting the sample between two conducting parallel plates forming a capacitor. The sample temperature was controlled by thermometer contact to the sample and temperature controller. A computerized Impedance Analyzer IM3570 was used to measure the dielectric properties of the prepared samples at a temperature range between $\left(-50\right.$ and $200^{\circ} \mathrm{C}$ ) over a wide frequency range from $10^{2}$ up to $10^{6} \mathrm{~Hz}$. The permittivity $\varepsilon^{\prime}$ and AC conductivity $\sigma_{\mathrm{AC}}$ were calculated from the output parameters like capacitance $C$ and loss tangent $\tan (\delta)$ as follows:

$$
\begin{aligned}
& \varepsilon^{\prime}=\frac{C d}{\varepsilon_{0} A}, \\
& \sigma_{\mathrm{AC}}=\omega \varepsilon_{0} \varepsilon^{\prime} \tan (\delta),
\end{aligned}
$$

where $\varepsilon_{0}$ is the permittivity of free space $\left(8.854 \times 10^{-12} \mathrm{~F} / \mathrm{m}\right), d$ is the sample thickness, and $A$ is the sample surface area. The measurement uncertainty reported to be $\pm 1 \%$ and $\pm 3 \%$ in $\varepsilon^{\prime}$ and $\tan (\delta)$, respectively. The measurement reproducibility was tested by re-measuring $\varepsilon^{\prime}$ and $\tan (\delta)$ after experimenting once again.

\section{Results and discussion}

\subsection{Structure and morphology study}

Figure 1 illustrates XRD patterns for $\mathrm{BTO}_{3}$ and $\mathrm{BTSO}_{3}: 2 \mathrm{Er}$ powders annealed in air at $1050{ }^{\circ} \mathrm{C}$ for $4 \mathrm{~h}$. It can be seen that all the observed peaks corresponding to $\mathrm{BTO}_{3}$ tetragonal perovskite structure were presented in all patterns according to ICDD number [74-2491]. It is evident that the BTSO:2Er sample contains traces of $\mathrm{SnO}_{2}$ without secondary phases results from $\mathrm{Er}^{3+}$ doping; referring to $\mathrm{Er}^{3+}$ nominally substitute for $\mathrm{Ti}^{4+}$ site and well soluble in host material due to its lower concentration. In $\mathrm{BTSO}_{3}: 2 \mathrm{Er}$, a preferential substitution $\mathrm{Er}^{3+}$ for $\mathrm{B}$ sites is postulated in $0 \leq \mathrm{Er}^{3+} \leq 0.03$ composition range as well as the non-total stabilization of these parameters for $0.03 \leq \mathrm{Er}^{3+} \leq 0.30[20]$. Figure $1 \mathrm{~b}$ shows the expanding area between $2 \theta=40^{\circ}$ and $2 \theta=49^{\circ}$ for both samples, which highlighted the splitting of (002) and (200) orientations at around $45^{\circ}$ in $2 \theta$ scale, exploring the tetragonal feature for $\mathrm{BTO}_{3}$ [21]. The splitting taken as $2 \theta$ distance between the peaks is large enough to confirm tetragonality for $\mathrm{BTO}_{3}$ whereas it decreased for $\mathrm{BTSO}_{3}: 2 \mathrm{Er}$, referring to tetragonality decrease as confirmed by the calculations listed in Table I. 

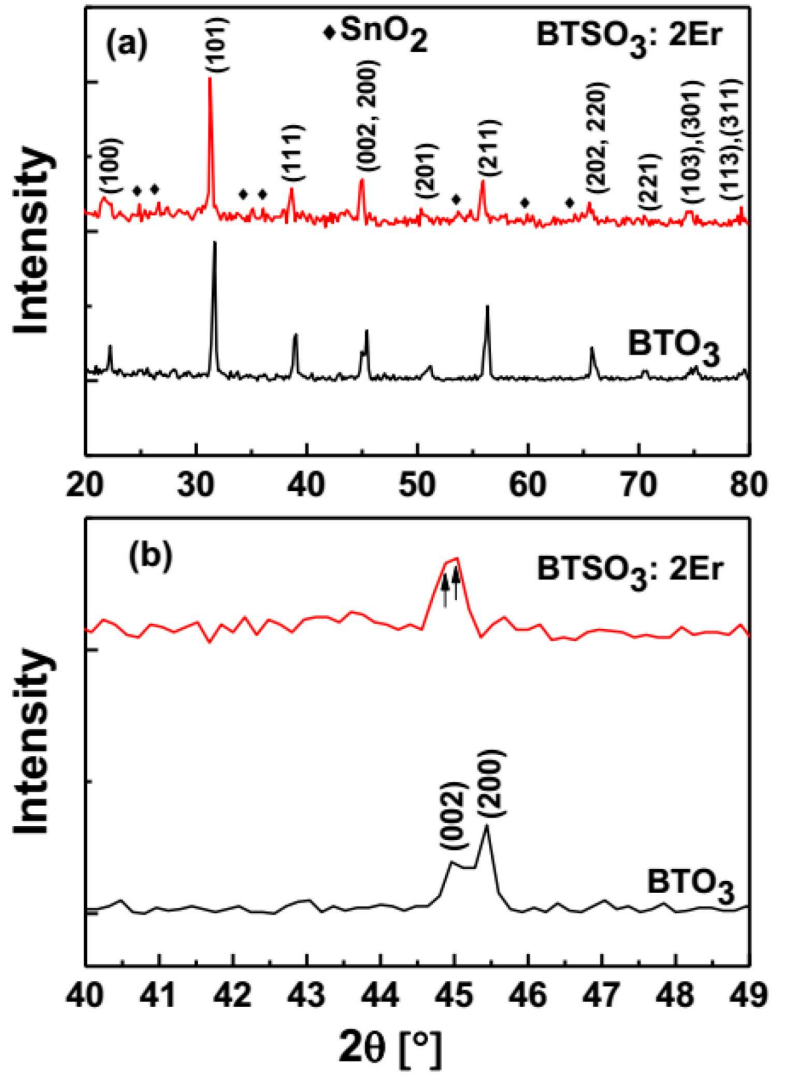

Fig. 1. XRD patterns of nano-crystalline $\mathrm{BTO}_{3}$ and $\mathrm{BTSO}_{3}: 2 \mathrm{Er}$ samples sintered in air for $4 \mathrm{~h}$ at $1050^{\circ} \mathrm{C}(\mathrm{a})$, and those for expanding area between $2 \theta=44^{\circ}$ and $46^{\circ}(\mathrm{b})$.

TABLE I

Calculated crystallite size (CS), lattice parameters $(a, c)$, and tetragonal factor $(c / a)$ for $\mathrm{BTO}_{3}$ and $\mathrm{BTSO}_{3}: 2 \mathrm{Er}$

\begin{tabular}{l|c|c|c|c}
\hline \hline \multicolumn{1}{c|}{ Samples } & CS [nm] & $a[\AA]$ & $c[\AA]$ & $c / a$ \\
\hline $\mathrm{BTO}_{3}$ & 64 & 3.9888 & 4.020 & 1.0078 \\
$\mathrm{BTSO}_{3}: 2 \mathrm{Er}$ & 57.11 & 4.0000 & 4.0052 & 1.0013
\end{tabular}

To calculate the tetragonality factor, the lattice parameters $(a, c)$ should be calculated at first from the following equation:

$$
d_{h k l}=\frac{a}{\sqrt{h^{2}+k^{2}+\left(\frac{a}{c}\right)^{2} l^{2}}},
$$

where $d_{h k l}$ is the $d$-spacing for the $(h k l)$ plane. Table I shows the crystallite sizes, lattice parameters $(a, c)$ and tetragonal factor for $\mathrm{BTO}_{3}$ and $\mathrm{BTSO}_{3}: 2 \mathrm{Er}$ using the planes (200) and (002). The average crystallite size was found to be 64 and $57.11 \mathrm{~nm}$ for $\mathrm{BTO}_{3}$ and $\mathrm{BTSO}_{3}: 2 \mathrm{Er}$, respectively, confirming that the samples were successfully prepared in the nanoscale.

FESEM microphotographs and the corresponding EDX images for $\mathrm{BTO}_{3}$ and $\mathrm{BTSO}_{3}: 2 \mathrm{Er}$ samples, are together illustrated in Figs. 2 and 3. It turns out that both

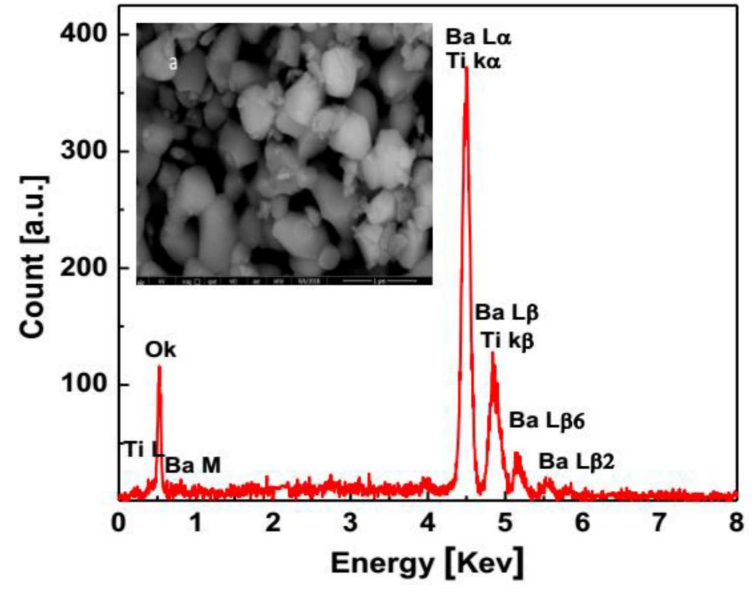

Fig. 2. FESEM/EDX image for $\mathrm{BTO}_{3}$ sintered in air for $4 \mathrm{~h}$ at $1050^{\circ} \mathrm{C}$.

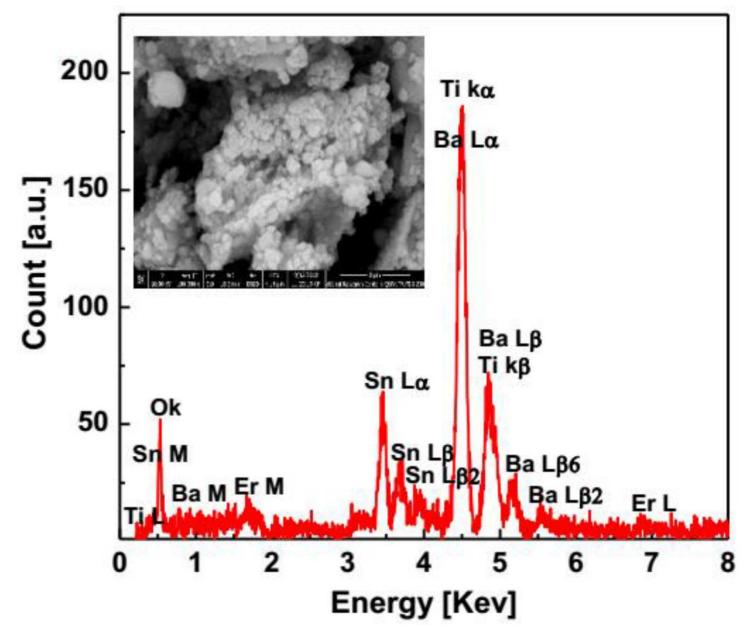

Fig. 3. FESEM/EDX image for $\mathrm{BTSO}_{3}: 2 \mathrm{Er}$ sintered in air for $4 \mathrm{~h}$ at $1050^{\circ} \mathrm{C}$.

samples show free uniform grains. Inset of Fig. 3 and Table I show that the compensation mode of $\mathrm{Sn}^{4+} / \mathrm{Er}^{3+}$ ions in $\mathrm{BaTiO}_{3}$ can suppress grain growth, forming a uniform and fine-grained microstructure with an average grain size of $57.11 \mathrm{~nm}$. Further, the surface morphology of $\mathrm{BTSO}_{3}: 2 \mathrm{Er}$ shows different microstructure features due to doping with $\mathrm{Sn}^{4+}$ and $\mathrm{Er}^{4+}$ ions which have larger ionic radii than $\mathrm{Ti}^{4+}$. Accordingly, $\mathrm{BTSO}_{3}: 2 \mathrm{Er}$ has higher densification than pure $\mathrm{BTO}_{3}$. To identify the purity of nanoparticle samples, dispersive X-ray analysis (EDX) is investigated. $\mathrm{BTO}_{3}$ has high-intensity peaks corresponding to oxygen, $\mathrm{Ba}$, and $\mathrm{Ti}$ elements, confirming the absence of any impurities. Similar peaks with lower intensities and additional peaks corresponding to $\mathrm{Sn}$ and Er elements are noticed for $\mathrm{BTSO}_{3}: 2 \mathrm{Er}$ sample (Fig. 3).

FTIR spectra for $\mathrm{BTO}_{3}$ and $\mathrm{BTSO}_{3}: 2 \mathrm{Er}$ samples, are shown in Fig. 4. For $\mathrm{BTO}_{3}$ spectra, the weak band at $549 \mathrm{~cm}^{-1}$ is assigned to $\mathrm{M}-\mathrm{O}$ stretching vibration of 


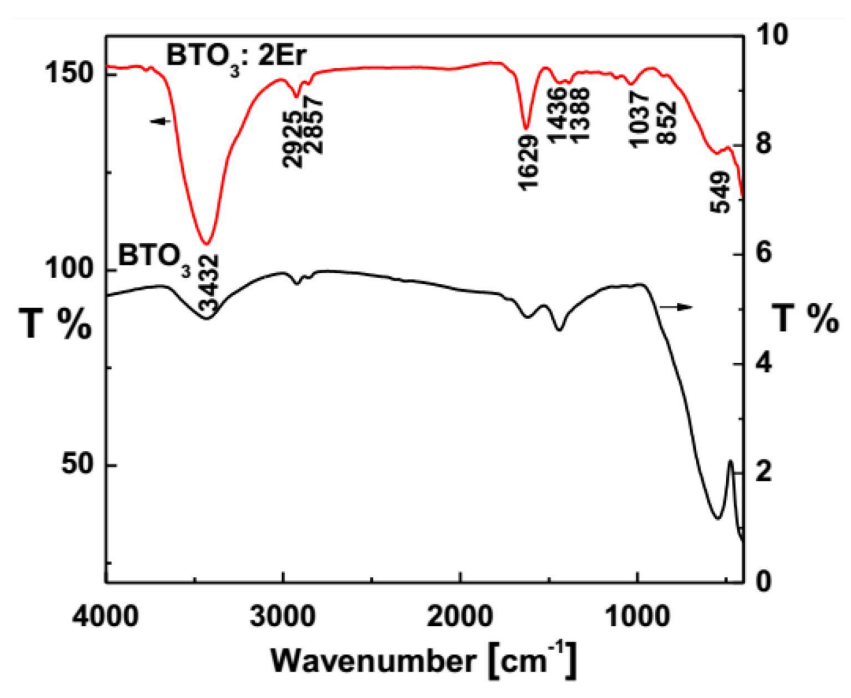

Fig. 4. FTIR spectra of $\mathrm{BTO}_{3}$ and $\mathrm{BTSO}_{3}: 2 \mathrm{Er}$ sintered in air for $4 \mathrm{~h}$ at $1050{ }^{\circ} \mathrm{C}$.

TABLE II

Assignment for FTIR data of $\mathrm{BTO}_{3}$ and $\mathrm{BTSO}_{3}: 2 \mathrm{Er}$

\begin{tabular}{|c|c|c|}
\hline No. & $\begin{array}{c}\text { Frequency } \\
{\left[\mathrm{cm}^{-1}\right]}\end{array}$ & Band assignment \\
\hline 1 & 549 & $\mathrm{~T}-\mathrm{O}$ stretching vibration \\
\hline 2 & 852 & $\begin{array}{l}\text { Ti-O or Sn-O or } \mathrm{Er}-\mathrm{O} \\
\text { stretching vibration }\end{array}$ \\
\hline 3 & 1037 & $\mathrm{CO}_{3}^{2-}$ bending vibration \\
\hline 4 & 1388,1436 & $\mathrm{CO}_{3}^{2-}$ stretching vibration \\
\hline 5 & 1629 & $\mathrm{O}-\mathrm{H}$ bending vibration \\
\hline 6 & 2857 & C-H stretching vibrations ( $\mathrm{CH}_{2}$ group) \\
\hline 7 & 2925 & $\mathrm{C}-\mathrm{H}$ stretching vibrations $\left(\mathrm{CH}_{3}\right.$ group $)$ \\
\hline 8 & 3432 & $\mathrm{O}-\mathrm{H}$ stretching vibration \\
\hline
\end{tabular}

octahedral $\mathrm{TiO}_{6}$ [22-24], whereas the band at $1436 \mathrm{~cm}^{-1}$ is assigned to lattice carbonate [25]. However, the last band has no evidence in XRD spectra due to the smaller particle size of lattice carbonate than the Bragg size, exploring more sensitivity of FTIR than XRD technique. The band at $1629 \mathrm{~cm}^{-1}$ is assigned to the $\mathrm{O}-\mathrm{H}$ decomposition mode of absorbed water molecules and attributed to the bending vibration. The bands at 2925 and $2857 \mathrm{~cm}^{-1}$ are assigned to the $\mathrm{CH}_{3}$ symmetric and $\mathrm{CH}_{2}$ symmetric stretching $\mathrm{C}-\mathrm{H}$ vibrations, respectively [26, 27]. The broad low-intensity band appearing at $3432 \mathrm{~cm}^{-1}$ is assigned to $\mathrm{O}-\mathrm{H}$ stretching modes of surface adsorbed water. It describes the stretching vibration of weakly bound water interacting via hydrogen bond with its environment and also to stretching vibrations of hydrogen-bonded of OH-groups [28, 29].

FTIR spectra for $\mathrm{BTSO}_{3}: 2 \mathrm{Er}$ sample shows all previous bands with extra two bands as listed in Table II. One band at $852 \mathrm{~cm}^{-1}$ is assigned to $\mathrm{M}-\mathrm{O}$ stretching vibration that results from tetrahedral sites and oxygen complexes [14] due to co-doping, whereas the second band at $1037 \mathrm{~cm}^{-1}$ is assigned to $\mathrm{CO}_{3}^{2-}$ bending vibration. Further, there is a coexistence of $\mathrm{OH}$ stretching (at $3432 \mathrm{~cm}^{-1}$ ) with the carbonate at 1037 and $1386 \mathrm{~cm}^{-1}$, suggesting that carbonate would exist as hydroxycarbonate. Extensive work is needed to validate this point and to evaluate the possible reactions with air after annealing (and before FTIR experiments) which may contribute to carbonate and $\mathrm{OH}$ group [30]. This reaction is more active for the co-doped sample appearing as a strong band at $3432 \mathrm{~cm}^{-1}$ and additional carbonate bands.

\subsection{Dielectric study}

The dielectric studies for $\mathrm{BTO}_{3}$ and $\mathrm{BTSO}_{3}: 2 \mathrm{Er}$ sample included two parts. The first study involved the effect of temperature and frequency on permittivity $\left(\varepsilon^{\prime}\right)$. The second study was concerned with the frequency and temperature dependences of AC conductivity $\left(\sigma_{\mathrm{AC}}\right)$.

\subsubsection{Temperature dependence of permittivity}

The permittivity (Fig. 5b) was investigated for $\mathrm{BTO}_{3}$ (Fig. 5a) and $\mathrm{BTSO}_{3}: 2 \mathrm{Er}$ ) samples over a wide temperature range $\left(-50\right.$ to $\left.200^{\circ} \mathrm{C}\right)$ and a frequency range $\left(10^{2}-10^{5} \mathrm{~Hz}\right)$. As a general description, $\varepsilon^{\prime}$ for both samples exhibits high values in the low-frequency region, followed by a significant decrease at high frequencies, in agreement with the result reported for the compounds based relaxor ferroelectric materials $[12,20]$. Further, the decrease in permittivity with frequency increase is commonly due to decrease in the total polarization components, i.e., space charge, dipolar, ionic, and atomic polarization. The last two polarizations are excluded from further discussion because their mechanisms are determined at very high frequencies $\left(>10^{14} \mathrm{~Hz}\right)$ out of our frequency window. In Fig. $5 \mathrm{a}, \varepsilon^{\prime}$ of $\mathrm{BTO}_{3}$ shows three successive relaxation peaks corresponding to three structural transitions. The first is the sharpest and highest intensity peak whose maximum is determined at $125^{\circ} \mathrm{C}$, revealing the tetragonal-cubic phase transition temperature, i.e. the Curie temperature $\left(T_{\mathrm{C}}\right)$ [31]. The second is a relatively broad and low-intensity peak, determined at $30^{\circ} \mathrm{C}$, that specifies tetragonal-orthorhombic phase transition temperature $\left(T_{\mathrm{T}-\mathrm{O}}\right)$, while the last one is a weaker relaxation peak whose maximum positioned at $-35^{\circ} \mathrm{C}$ corresponds to orthorhombic-rhombohedral phase transition temperature $\left(T_{\mathrm{O}-\mathrm{R}}\right)$, as shown in Table III. These transitions have been typically found for all classical ferroelectric materials [32].

TABLE III

Phase transition temperatures for $\mathrm{BTO}_{3}$ and $\mathrm{BTSO}_{3}: 2 \mathrm{Er}$

\begin{tabular}{l|c|c|c|c}
\hline \hline \multirow{2}{*}{ Sample } & \multicolumn{4}{|c}{ Phase Transition Temperatures $\left[{ }^{\circ} \mathrm{C}\right]$} \\
\cline { 2 - 5 } & $T_{\mathrm{O}-\mathrm{R}}$ & $T_{\mathrm{T}-\mathrm{O}}$ & $T_{\mathrm{C}}\left(T_{\mathrm{C}-\mathrm{T}}\right)$ & $>T_{\mathrm{C}}$ \\
\hline $\mathrm{BTO}_{3}$ & -35 & 30 & 125 & $\mathrm{ND}^{*}$ \\
$\mathrm{BTSO}_{3}: 2 \mathrm{Er}$ & $\mathrm{ND}^{*}$ & -6 & 100 & 174 \\
\hline & ${ }^{*}$ non-detected
\end{tabular}




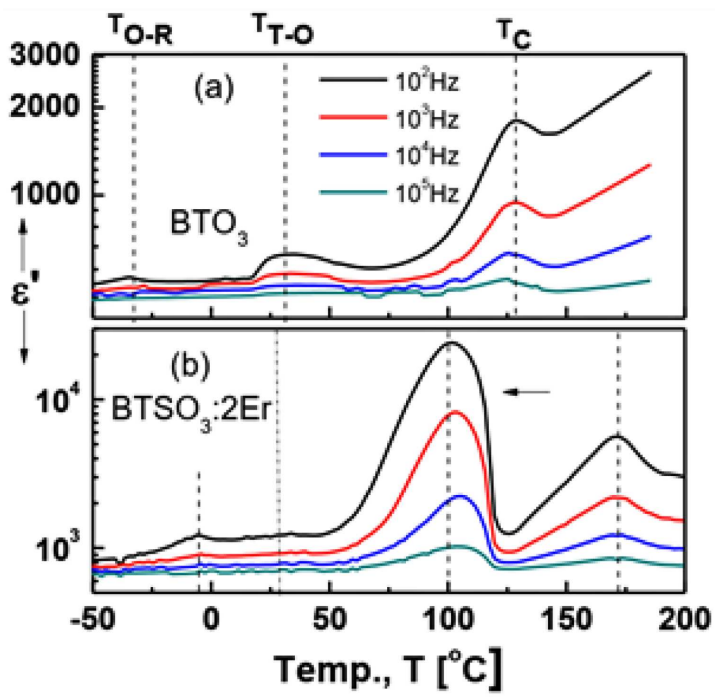

Fig. 5. Temperature dependence of permittivity $\left(\varepsilon^{\prime}\right)$ at different frequencies for $\mathrm{BTO}_{3}$ (a) and $\mathrm{BTSO}_{3}: 2 \mathrm{Er}(\mathrm{b})$, sintered in air for $4 \mathrm{~h}$ at $1050^{\circ} \mathrm{C}$.

For $\mathrm{BTSO}_{3}: 2 \mathrm{Er}$ sample (Fig. 5b), the shape of $\varepsilon^{\prime}$ curves significantly changed and the phase transition temperatures shifted to lower values. Similar behavior has been reported previously upon the incorporation of Sn ions or/and addition of more than $2 \mathrm{~mol} \%$ Er into the stoichiometric $\mathrm{BTO}_{3}[33,34]$. Therefore, Er-doped samples reported no changes in $T_{\mathrm{C}}$ when the concentration of Er ions is lower than $2 \mathrm{~mol} \%$. As a result, one may attribute the changes occurring in $T_{\mathrm{C}}$ of $\mathrm{BTSO}_{3}: 2 \mathrm{Er}$ sample to the presence of $\mathrm{Sn}^{4+}$ ions instead of less effective $\mathrm{Er}^{3+}$ ions at low concentrations.

Accordingly, doping with $\mathrm{Sn}^{4+}$ results in a remarkable permittivity increase as compared to that reported for pure $\mathrm{BTO}_{3}$ sample, i.e., it is 1151 at room temperature and 24221 at $T_{\mathrm{C}}$. This reveals enhanced dielectric properties upon doping $\mathrm{BTO}_{3}$ with $\mathrm{Sn}^{4+}$ ions. The degree of enhancement is larger than those reported for $\mathrm{BaTO}_{3}$ doped with other ions, i.e., $\mathrm{Co}^{2+}, \mathrm{Bi}^{+2}, \mathrm{La} / \mathrm{Mn}$, and $\mathrm{Y}^{3+} / \mathrm{Nb}^{5+}[35-39]$. The possible reasons for that would be explained based on a specific amount of space charge sites produced inside the grain boundaries and domain walls. Therefore, the space charge itself creates an opposite electric field hindering the polarization that originates from movements of domain walls and grain boundaries. However, as the densification of $\mathrm{BaTO}_{3}$ is increased, the space-charge fields would be easily reduced by space charge of the surrounding grains. Thus, the domain walls become quite free in denser ceramics, causing a polarization increase that results in a considerable permittivity increase. Another reason may come from the large bond length in the case of $\mathrm{Er}-\mathrm{O}$ and $\mathrm{Sn}-\mathrm{O}$ than $\mathrm{Ti}-\mathrm{O}$.

Furthermore, $\varepsilon^{\prime}$ of $\mathrm{BTSO}_{3}: 2 \mathrm{Er}$ sample exhibits an unexpected relaxation peak whose maximum is positioned at a temperature higher than $T_{\mathrm{C}}\left(\sim 174^{\circ} \mathrm{C}\right)$. Less attention has been paid to discuss the possible reason for
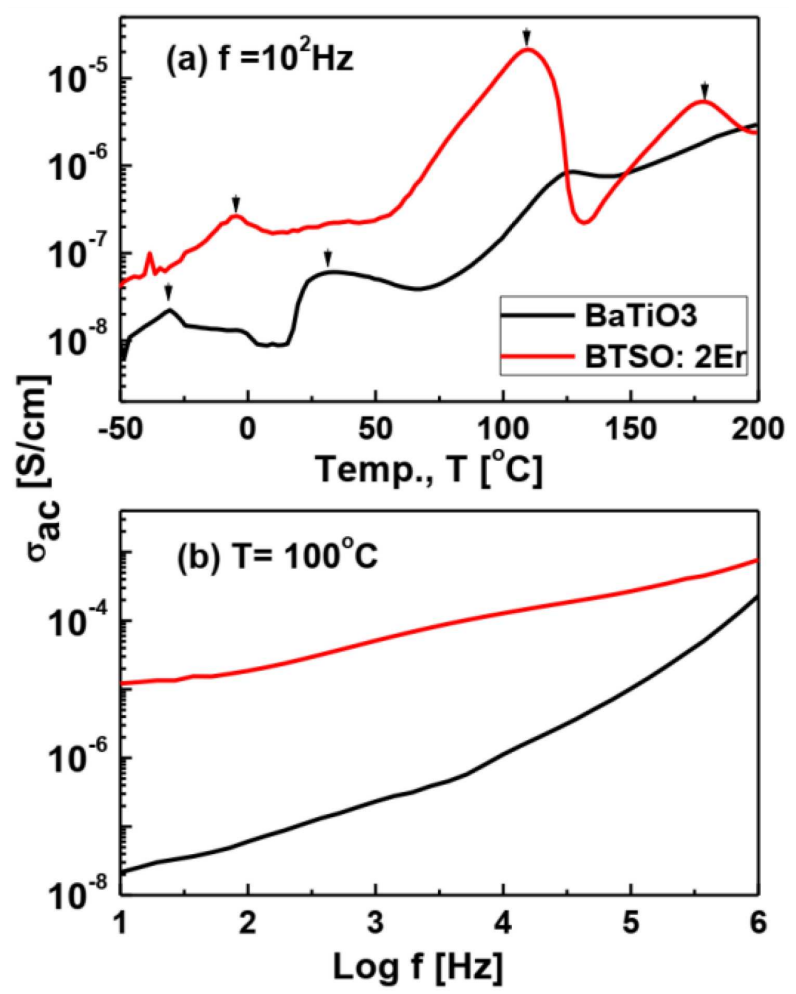

Fig. 6. Temperature (a) and frequency (b) dependence of $\mathrm{AC}$ conductivity $\left(\sigma_{\mathrm{AC}}\right)$ for $\mathrm{BTO}_{3}(\mathrm{a})$ and $\mathrm{BTSO}_{3}$ : $2 \mathrm{Er}(\mathrm{b})$, sintered in air for $4 \mathrm{~h}$ at $1050^{\circ} \mathrm{C}$. The arrows indicate the phase transition temperatures.

such a peak and therefore it is still an open point for future discussion. According to best of our knowledge, we suggest that the orientation polarization of aggregated $\mathrm{SnO}_{2}$ inside the ceramic whose traces appeared in XRD analysis (Fig. 1a), is responsible for such a peak. It can also be noticed from Fig. $5 \mathrm{~b}$ that $T_{\mathrm{C}}$ of doped samples shifts to higher temperatures with increasing frequency which may reveal the relaxor ferroelectrics [7, 8].

\subsubsection{Temperature and frequency dependence of conductivity}

To investigate the relation between the observed relaxation peaks and transportation of free charge carriers through the crystalline lattice, $\mathrm{AC}$ conductivity $\left(\sigma_{\mathrm{AC}}\right)$ for both $\mathrm{BTO}_{3}$ and $\mathrm{BTSO}_{3}: 2 \mathrm{Er}$ samples is studied at first as a function of temperature at $10^{2} \mathrm{~Hz}$ (Fig. 6a) and then as a function of frequency at $100^{\circ} \mathrm{C}$ (Fig. 6b). In Fig. 6a, $\sigma_{\mathrm{AC}}$ for both samples starts to slightly increase with increasing temperature and then shows anomalous behavior near the structure transition temperatures. Thus, it exhibits also three pronounced relaxation peaks confirming the phase transition feature for the investigated samples. It can also be noticed that a peak position shifts to higher values for $\mathrm{BTSO}_{3}: 2 \mathrm{Er}$ sample. The conduction at temperatures below $T_{C}$, within the tetragonal ferroelectric may originate from the presence of impurities or defects. Oxygen vacancies as most mobile ionic defects in 
perovskite could be responsible for the conduction process [4]. At a temperature higher than $T_{\mathrm{C}}$, within the cubic paraelectric phase, the electrical conduction could be due to thermally activated ionic hopping of oxygen vacancies in $\mathrm{BTSO}_{3}: 2 \mathrm{Er}$.

On the other side, the frequency-dependent conductivity (Fig. 6b) for both samples displays an increase with a frequency increase, obeying the universal powerlaw $A \omega^{s}[41,42]$. This arises from the long-range movements and alignments of free charge carriers towards the electric field, resulting in a net flow of charge through samples. The conductivity value of $\mathrm{BTSO}_{3}: 2 \mathrm{Er}$ is $\sim 10^{3}$ times higher than that for barium titanate sample, due to formation of excess oxygen vacancies.

\section{Conclusion}

Nano-powdered pure and $\mathrm{Sn}^{4+} / \mathrm{Er}^{3+}$ co-doped $\mathrm{BTO}_{3}$ ceramics have been successfully synthesized using the modified sol-gel method. The obtained gel converted to crystalline tetragonal powder upon annealing in air at $1050{ }^{\circ} \mathrm{C}$ for $4 \mathrm{~h}$. Upon co-doping with $\mathrm{Sn}^{4+} / \mathrm{Er}^{3+}$ ions, microstructure and dielectric properties significantly changed as follows:

1. Grains became denser and their sizes decreased from 64 to $57.11 \mathrm{~nm}$.

2. The Curie temperature $\left(T_{\mathrm{C}}\right)$ shifted from 125 to $103^{\circ} \mathrm{C}$.

3. The permittivity of $\mathrm{BTSO}_{3}: 2 \mathrm{Er}$ sample increased to become approximately ten times greater than that of pure $\mathrm{BTO}_{3}$.

4. AC conductivity value was found to be $\sim 10^{3}$ times higher than that for pure $\mathrm{BTO}_{3}$, leading to possibility of using $\mathrm{BTSO}_{3}: 2 \mathrm{Er}$ in the field of electrical capacitor fabrication.

5. An unexpected relaxation peak whose maximum was positioned beyond $T_{\mathrm{C}}\left(174^{\circ} \mathrm{C}\right)$ in the permittivity and $\mathrm{AC}$ conductivity spectra. It may have originated from the orientation polarization of aggregated $\mathrm{SnO}_{2}$ inside the ceramic.

\section{Acknowledgments}

Providing financial support of this work under Imhotep project 2018-2020 (grant No. 39521QE). A special thanks to National Research Centre, Dokki, and Giza for the laboratory facilities and continual encouragement. The authors extend the thankfulness to the ministries of Europe and Foreign Affairs (MEAE) and Higher Education Research and Innovation (MESRI) and in France Program Hubert Curien (PHC-Imhotep No. 39521QE) as a participating in financial support and Imhotep project $2018-2020$.
The authors would like to express their special thanks of gratitude to Professors: A. Lahmar, M. El Marssi, and A. Zeinert, LPMC, Université de Picardie Jules Verne, Amiens, France, for giving them the opportunity to measure the dielectric properties of the samples.

\section{References}

[1] R. Asiaie, W. Zhu, S. Ak, P. Dutta, Chem. Mater. 8 226 (1996).

[2] X. Yang, D. Li, Z. Ren, et al., RSC Adv. 6, 75422 (2016).

[3] T. Lee, C. Huang, C. Chang, I.-Kuan Cheng, C.-Li Hu, C.-Te Lee, M. Fujimoto, J. Mater. Res. 27, 2495 (2012).

[4] H. Dah, I. Chironi, I. Karatchevtseva, G. Triani, C. Sorrel, Adv. Appl. Ceram. 111, 149 (2012).

[5] G. Samara, J. Phys. Condens. Matter 15, R367 (2003).

[6] F. Jona, G. Shirane, Ferroelectric Crystals, Pergamon Press, Oxford (UK) 1963.

[7] Y. Liu, R. Withers, B. Nguyen, K. Elliott, Appl. Phys. Lett. 91, 152907 (2007).

[8] G. Smolensky, V. Isupov, Dokl. Akad. Nauk SSSR 96, 53 (1954).

[9] G. Haertling, J. Am. Ceram. Soc. 82, 797 (1999).

[10] X. Wei, X. Yao, Mater. Sci. Eng. B 137, 184 (2007).

[11] Y. Leyet, R. Peña, Y. Zulueta, F. Guerrero, J. Anglada-Rivera, Y. Romaguera, J. Pérez de la Cruz, Mater. Sci. Eng. B 177, 832 (2012).

[12] Y. Tsur, T. Dunbar, C. Randall, J. Electroceram. 7, 25 (2001).

[13] M.T. Buscaglia, M. Viviani, V. Buscaglia, C. Bottino, P. Nanni, J. Am. Ceram. Soc. 85, 1569 (2002).

[14] J. Hwang, Y. Han, J. Appl. Phys. 40, 676 (2001).

[15] S. Singh, P. Singh, O. Parkash, D. Kumar, J. Alloys Comp. 493, 522 (2010).

[16] Y.A. Zulueta, F. Guerrero, Y. Leyet, J. AngladaRivera, R.L. González-Romero, J. Meléndez, J. Phys. Status Solidi B 252, 508 (2015).

[17] P. Harold, E. Leroy, X-ray Diffraction Procedure: For Polycrystalline and Amorphous Materials Wiley, New York 1974

[18] E. Antonelli, M. Letonturier, J.C. Mepeko, J. Eur. Ceram. Soc. 29, 1449 (2009).

[19] T. Mandal, J. Mater. Lett. 61, 850 (2007).

[20] K. Uchino, E. Sadanaga, T. Hirose, J. Am. Ceram. Soc. 72, 1555 (1989).

[21] K. Fukai, K. Hidaka, M. Aoki, K. Abe, Ceram. Int. 16, 285 (1990).

[22] T. Yamamoto, K. Urabe, H. Banno, Jpn. J. Appl. Phys. 32, 4272 (1993).

[23] L. Songwei, I. Burtrand, M. Larry, J. Mater. Res. Bull. 35, 1303 (2000)

[24] S. Chang, W. Liao, C. Ciou, J. Lee, C. Li, J. Coll. Interface Sci. 329, 300 (2009).

[25] G. Chen, Y. Liu, Z. Zhang, B. Aghahadi, G. Somesfalean, Q. Sunand, F. Wang, Chem. Phys. Lett. 448, 127 (2007). 
[26] M. Cernea, J. Optoelectron. Adv. Mater. 7, 3015 (2005).

[27] H. Zhang, C. Kam, Y. Zhou, X. Han, Y. Lam, Y. Chan, K. Pita, Mater. Chem. Phys. 63, 174 (2000).

[28] R. Ganapathi, K. Chidambara, R. Lakshmi, V. Nirupama, J. Mater. Sci. Mater. Electron. 30, (2019).

[29] T. Supin, J. Milne, J. Non-Cryst. Solids 351, 976 (2005).

[30] K. Kao, in: Dielectric Phenomena in Solids, Ferroelectrics, Piezoelectrics and Pyroelectrics, 1st ed., Elsevier, 2004, p. 213 .

[31] A. Ayesh, R. Abdel-Rahem, Bull. Mater. Sci. 33, 589 (2010).

[32] S. Upadhyay, V. Reddy, P. Bag, R. Rawat, S. Gupta, A. Gupta, Appl. Phys. Lett. 105, 112907 (2014).

[33] S. Marković, M. Mitrić, N. Cvjetićanin, D. Uskokovic, Mater. Sci. Forum 518, 241 (2006).
[34] V. Shvartsman, J. Dec, Z. Xu, J. Banys, P. Keburis, W. Kleemann, Phase Transit. 81, 1013 (2008).

[35] Z. Zhuang, M. Hamer, D. Smyth, Mater. Res. Bull. 22, 1329 (1987).

[36] P. Krishna, D. Pandey, V. Tiwari, R. Chakravathy, B. Dasannacharya, Appl. Phys. Lett. 62, (1993).

[37] S. Lee, C. Randall, Appl. Phys. Lett. 92, 111904 (2008).

[38] L. Zhang, O. Thakur, A. Feteira, G. Keith, A. Mould, Appl. Phys. Lett. 90,142914 (2007).

[39] L. Da-Yong, G. Xiang-Lu, W. Shan, Results Phys. 12, 585 (2019)

[40] K. Gschneider, L. Eyring, in: Handbook on the Physics and Chemistry of Rare Earths, North Holland, Amsterdam 1980.

[41] A. Jonscher, Thin Solid Films 100, 329 (1983).

[42] A. Jonscher, Nature 267, 673 (1977). 